\title{
Conscience - An Endangered Human Value?
}

\author{
Khurshid A Mattoo* \\ Department of Prosthodontics, College of dentistry, Jazan University, Jazan, (KSA)
}

*Corresponding author: Khurshid A Mattoo, Department of Prosthodontics, College of dentistry, Jazan University, Jazan, KSA.

Received Date: December 16, 2019

Published Date: January 07, 2020

\section{Opinion}

Human beings have a problem: in fact, a serious problem!

Being a part of medical academics for the last two decades, while trying to build good human values within myself and my students, it has come to my notice often, that while human beings have shown utmost concern about endangering living species, we have never taken a look at our values and observed which values have literally become obsolete among us. If the fear of the almighty God would be nonexistent among humans, then the only thing that would direct and judge us is our conscience and our ability to refine consciousness. Since the two attributes are completely different in the scientific world, for a nonscientific person they are no different. While the term consciousness is actually a job of a human mind which receives and processes the received information while storing it after refinement, the human conscience is the fundamental ability of a healthy human being to perceive right from wrong, truth from falsehood, just from unjust, good from evil, fair from unfair, honesty from dishonesty and to some extent the choice of peace than war. In short, if one cannot draw the line between the two, he may be declared mentally unhealthy. While the last century saw startling violations by doctors whether it was in Russia (electro - shocking political dissidents), Germany (barbaric medical experiments on prisoners), United states of America (Tuskegee experiments), India (organ trafficking and abortion abuse), this century is witnessing medical violation and corruption in every format of medical practice.

Last month I was a victim of a medical doctor who arrived 45 minutes late for my colonoscopy and forgot that the drug given intravenously half hour before must have lost its effect. He also violated all norms of informed consent, since he was taking my consent after giving three injections of sedatives while I was lying on the table fully sedated. Trust me, I approached the doctor through a very reliable source and the doctor was fully aware of my socioeconomic status. On another day, while accompanying my father to a famous doctor, I observed that the doctor had eight staff members working from 9 am to $9 \mathrm{pm}$ at his private residence. Guess what, all the staff members were the existing working staff of a government hospital, from where he was getting a huge sum of nonpracticing allowance, which in fact is given to doctors to enhance patient care at government hospitals. The private residence was no less than a mini hospital since they were also performing tests, selling lucrative commissioned medicines and giving the next appointment to the patient after the fees expires. I used the word famous doctor - guess why? Well the problem is not the doctors it is the people who see what they are actually doing, yet they label such people to be famous, well, good or excellent.

I beg to differ - since what I saw was nothing less than an organized crime involving hospital staff. Now let us focus on the issue of conscience. Among human beings, conscience is the highest authority within oneself, which monitors and determines the quality of human action. It is like a consultant within a doctor. Every time you get tempted, you consult your conscience. Even hypothetically speaking, Doctors are a part of the society who must have highest moral values, for other society members trust the profession and the professional blindly. We have never heard a female patient objecting to the removal of clothes at the instruction of a doctor even in the world's most conservative cultures. We have also observed people willing to participate in medical research despite knowing about the gross violations in medical research of the past.

Like other human beings, doctors also have only two choices - either to act in accordance with or against the conscience. While those who act in accordance with conscience allow them to improve and refine their inner peace, those who act against their conscience create soul itching, anxiety, phobias within their physical body, all of which eventually leads to stress. The stress of not earning more money has become less than the stress of letting money go. One needs to understand that the death of conscience occurs in stages 
and it reaches a stage where an individual no longer listens to his conscience. Like other people in the society (politicians, police officers, journalists, tax officials, lawyers and judges) who enjoy power over others, doctors should not be the one who instead of using their power for benefitting patients they use it for worldly and personal gains. Doctors should not succumb to corruption, in fact, if some societal, cultural, political or economic environment is influencing them to surrender, they should be the one to effect change of such influences. The presence of a clear conscience is a sign of good health, whereas the opposite is a sign of poor mental health. Conscience can rank higher than consciousness provided one develops higher perceptions of concepts like good, right, just, fair, peace, love and sets low values for concepts like greed, envy, sloth, pride, lust, war, etc. Compromise of conscience for the sake of survival is a farce and needs to be fought by every doctor whether he is a clinician or an academician. Present societies are contemporary and with the advent of social media, society is falling prey to pseudo competition and hypocritical behavior. Doctors are seen increasingly boasting their patient achievements on Facebook and Twitter and do not hesitate to post their patient pictures without having even the slightest conscience of not having taken the consent from their patients to do so.

The basic human functions like imagination, reasoning and memory are being lost without any evidence of illness, thus rendering conscience nonfunctional. Deception, lying, equivocating, fraudulence and jugglery are becoming norms and ways of cheating patients. Prescribing unnecessary tests and drugs not only cause harm to the patients, but indirectly are affecting the doctor's efficiency to diagnose diseases. Medical health care costs are becoming non - affordable for a large section of low- and middleclass society mainly due to lack of conscience among doctors. Conscience violation is not limited to, doctors in practice, but has spread to academicians also. Frauds in publishing research have still yet not been explored. In the near future, if necessary, steps are not taken to restore human values, the future generations will have nothing to live for. Doctors need to come forward in the society and set examples of restoring conscience whether through empathy or through confessions. The medical professionals need to restore the trust, that our forefathers have relished.

“The moment a human is conceived in a mother's womb, he becomes one in a trillion. His identification in this world is through the type of conscience he nurses. Lack of conscience indicates the death of that particular individual, although he is physically still present in this world".

\section{Acknowledgement}

None.

\section{Conflict of Interest}

No conflict of interest. 